\title{
Modelling the influence of friction coefficient on materials process by Equal Channel Angular Press technique
}

\author{
Kazeem O. Sanusi ${ }^{1, a}$, and Esther T. Akinlabi, ${ }^{1, b}$ \\ ${ }^{1}$ Department of Mechanical Engineering Science, University of Johannesburg, \\ Johannesburg 2006, South Africa. \\ asanusik@gmail.com, beTakinlabi@uj.ac.za
}

\section{Keywords: Abaqus, Copper alloy, ECAP, friction coefficient, Severe Plastic Deformation}

\begin{abstract}
In this paper, a commercial finite element software, ABAQUS was used to simulate the influence of friction coefficient on copper alloy process by Equal Channel Angular press technique. The geometry of the simulated samples is $7.3 \mathrm{~mm}$ width by $50 \mathrm{~mm}$ long. The die is analytical rigid, and the process was adiabatic at room temperature. The influence of friction was obtained with different friction coefficient. From the simulations results, the extent of inhomogeneous in the work-piece shows increase due to the frictional effects and this have a great influence on the deformation behaviour during ECAP process, the effect is particularly severe at the bottom of the work-piece. Finite element simulations will let us have a better understanding of heterogeneity, geometry, and help us in determining the best measurement regions regarding the deformation path.
\end{abstract}

\section{Introduction}

Severe Plastic Deformation (SPD) is an active processing technique uses for produce ultrafine grain materials (UFG) by introducing large plastic strains in metals to the reduce grain sizes. [1-5]. These UFG materials have some special properties that result from a large volume fraction of their grain and interphase boundaries [6-8]. These SPD techniques have provided new opportunities in the investigation of enhanced superplasicity in metal and alloys. The common SPD methods usually use are Equal Channel Angular Press technique, High Pressure Torsion and accumulative roll bonding [9].

The principle of Equal Channel Angular Pressing (ECAP) is at present the most developed processing technique for producing UFG's and NC metals and alloys. The technique was first introduced by Segal and his co-workers in the 1970's and 1980's at an institute in Minsk in the Soviet Union. The basic objective at that time was to develop a metal forming process where high strains may be introduced into metal billets by simple shear. It is the most efficient technique of Severe Plastic Deformation [9]. The method has been used effectively to control microstructure of metals by following different multi-pass routes. The technique has been used to achieve optimal grain refinement of metals and alloys and it can be applied to large billets so that there is the potential for producing materials that may be used in a wide range of structural applications [5].

The ECAP technique uses two channels with identical rectangular cross sections connected through the intersection at a specific angle, usually between $90^{\circ}$ and $135^{\circ}$ [1] and there is an additional angle, $\psi$, equal to $0^{\circ}$ which represents the outer arc of curvature where the two channels intercept. The cross section can be either circular or square. The specimen is machined to fit within the channel and the die is placed in some form of press so that the specimen can be pressed through the die using a plunger.

Friction is the most important boundary condition in ECAP and affects the uniformity of deformation such as the strain distribution and loading history. It has been discovered that frictional conditions are not identical in both channels [8] and it is especially difficult to provide low friction along a bottom wall of the second channel of high normal pressure and lubricant removal during extrusion [7]. The ECAP procedure is a metal flow process characterized by several fundamental parameters. The parameters include the strain imposed in each separate passage through the die and 
the slip systems operating during the pressing operation. All these parameters play a vital role to determine the nature of the UFG and NC structures introduced by ECAP.

In other to investigate the plastic deformation mechanisms of the work-piece during ECAP processing and to better understating the ECAP method during large deformation, a finite element analysis method was developed. Commercial finite element software, ABAQUS was used to simulate the anisotropic elastic-plastic flow of the material.
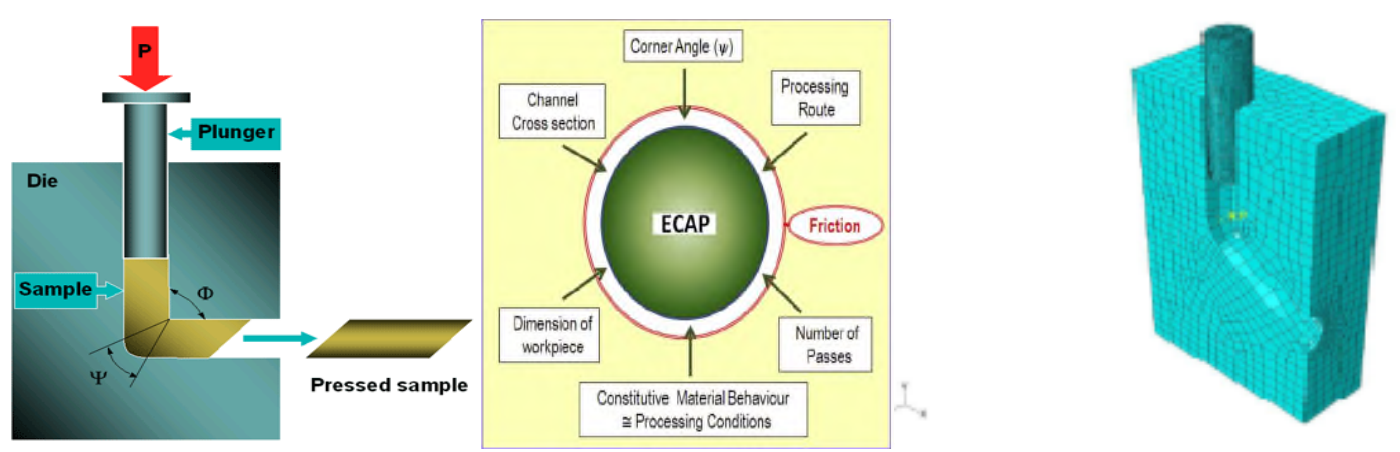

Fig. 1 The FEM modelling ECAP die tooling.

\section{Modelling and Simulation of ECAP Technique}

The simulations of the extrusion of metals during Equal Channel Angular Press technique was made by assuming isothermal conditions at room temperature and neglecting the heating conditions due to the friction between the work-piece and the die tool to determine the model behaviour of nanocrystalline metals and alloys. The numerical simulations were performed with commercial finite element code ABAQUS/explicit.

\section{Modelling of the Die}

The channels angle intersection angles considered for the model is 1260 , the outer intersection angle was assumed to be zero. The channels have a diameter of $7.4 \mathrm{~mm}$ and the die was assumed to be rigid-elastic pieces with element type R3D4 and the material used was a tool steel with young modulus $\mathrm{E}$ and the passion ratio $\mathrm{V}$ equal to $210,000 \mathrm{MPa}$ and 0.3 respectively. The details of the FEM modelling ECAP die tooling with channel angle 1260, are shown in Fig. 1.

\section{Modelling of the Work-Piece}

work-pieces assumed to have the dimensions of $7.3 \mathrm{~mm}$ (width) x $50 \mathrm{~mm}$ (height) and a unity thickness since a plane-strain condition is assumed. The material of the billet was assumed to be isotropic elastic-plastic, with element type C3D8 and its elastic properties were $\mathrm{E}=108,000 \mathrm{MPa}$, and $\mathrm{V}=0.31$ whereas the plasticity is defined by the von Mises or $\mathrm{J} 2$ associated flow rule.

Loadings and Work-Piece-Tooling Contact. The plunger was not taken into account in the finite element modelling. A displacement boundary condition was imposed on the top line of the work-piece. The compressive displacements imposed on the work-piece top region in the vertical direction were fixed in increment of $0.50 \mathrm{~mm}$ up to a total displacement of $40 \mathrm{~mm}$ in the direction of movement of the punch with a force of $70 \mathrm{kN}$. (See figure 5.3). For the frictional behaviour at the work-piece / die interface, the friction coefficient values of 0 and 0.1 were attributed at the models to carry out the simulation.

Mesh of the Work-Piece. 3481 elements are generated for the rod for 3-dimensional model via ALE method combined with remeshing technology to handle a large localized deformation occurred during the ECAP process. This method combines both the advantages of Eulerian and Lagragian representations and it is exploited to reduce finite element mesh distortions. 


\section{Experimental Results and Discussions}

Fig. 2-4 shows the equivalent von Mises distribution of ECAP process using coefficient of friction of 0 (frictionless) and 0.1. During the deformation, the front end of the work-piece sticks to the bottom of the die, and then the flow starts. The effect of friction on the deformation is inhomogeneous and non-uniform in the inner of the work-piece, which has severe effects at the bottom side of the work-piece. The von Mises distribution varies during the deformation process, there is a steady and uniform region of maximum equivalent von Mises distribution in the work-piece, the maximum equivalent von Mises can be achieved by a high value of $5.438 \mathrm{MPa}$ at the bottom side of the work-piece which is attributed to the effect of friction on the flow of the metal. From the figure in found that the increase in friction leads to increase in inhomogeneity, and the friction has very important role in the ECAP process.
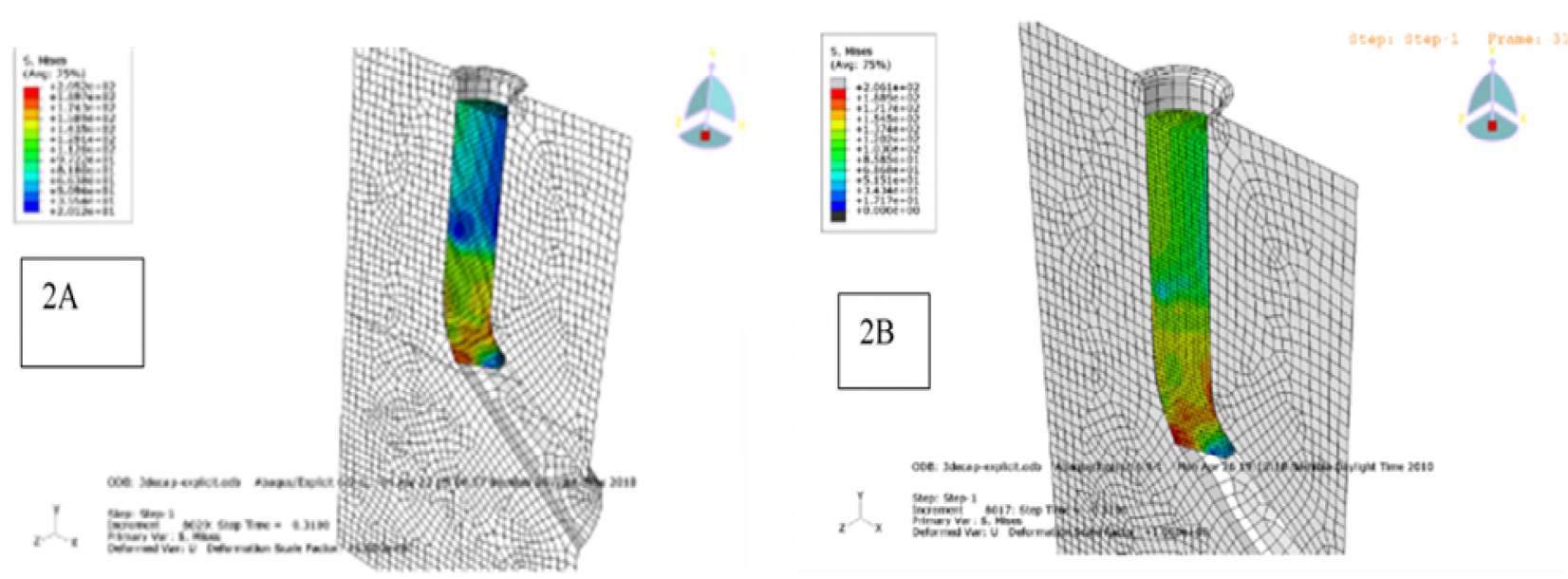

Fig. 2A shows the distribution of the effective stress obtained at time $t=0.31(\mu=0.0)$ and $2 \mathrm{~B}$ shows the distribution of the effective stress obtained at time $\mathrm{t}=0.31(\mu=0.1)$
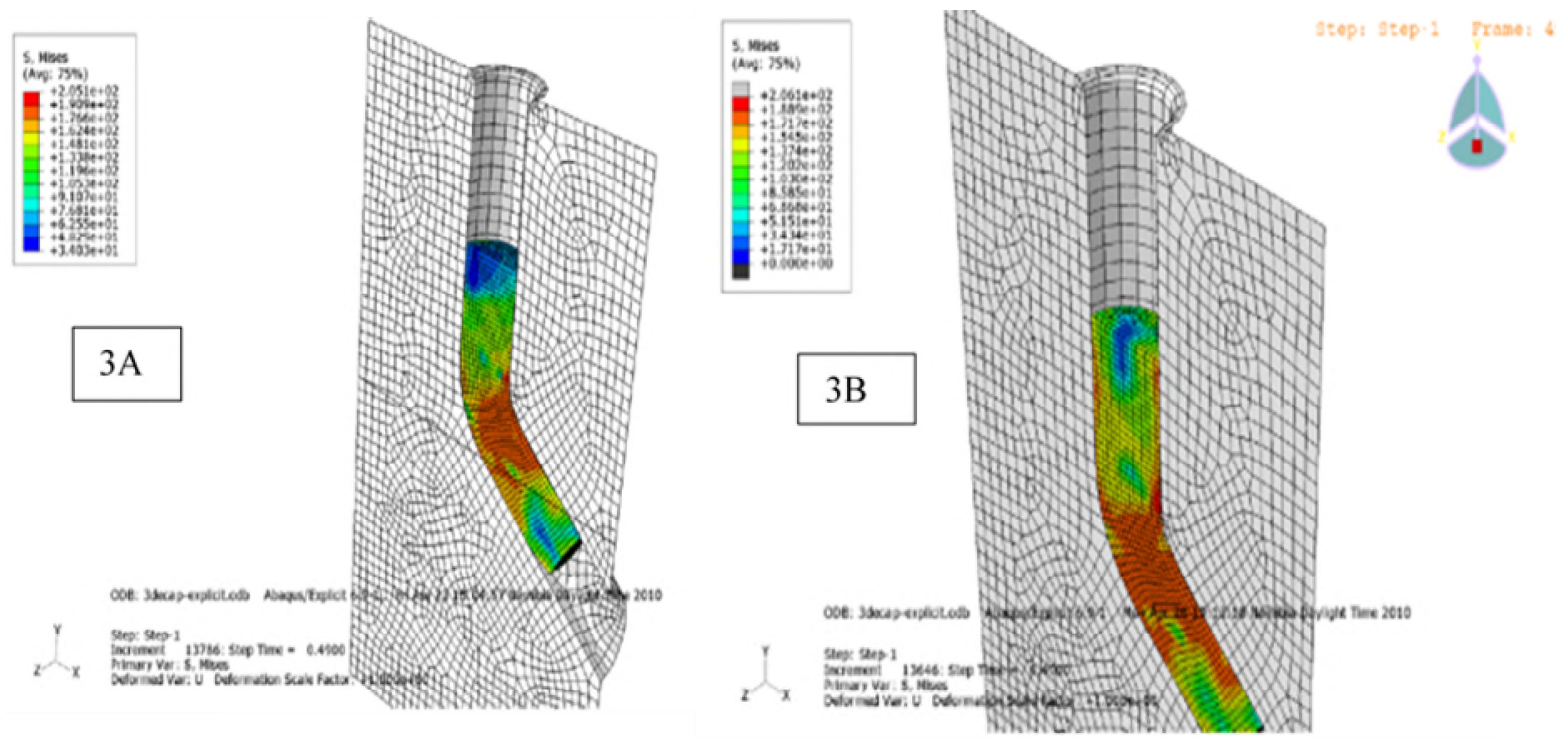

Fig. 3A shows the distribution of the effective stress obtained at time $t=0.49(\mu=0.0)$ and $3 \mathrm{~B}$ shows the distribution of the effective stress obtained at time $\mathrm{t}=0.49(\mu=0.1)$ 

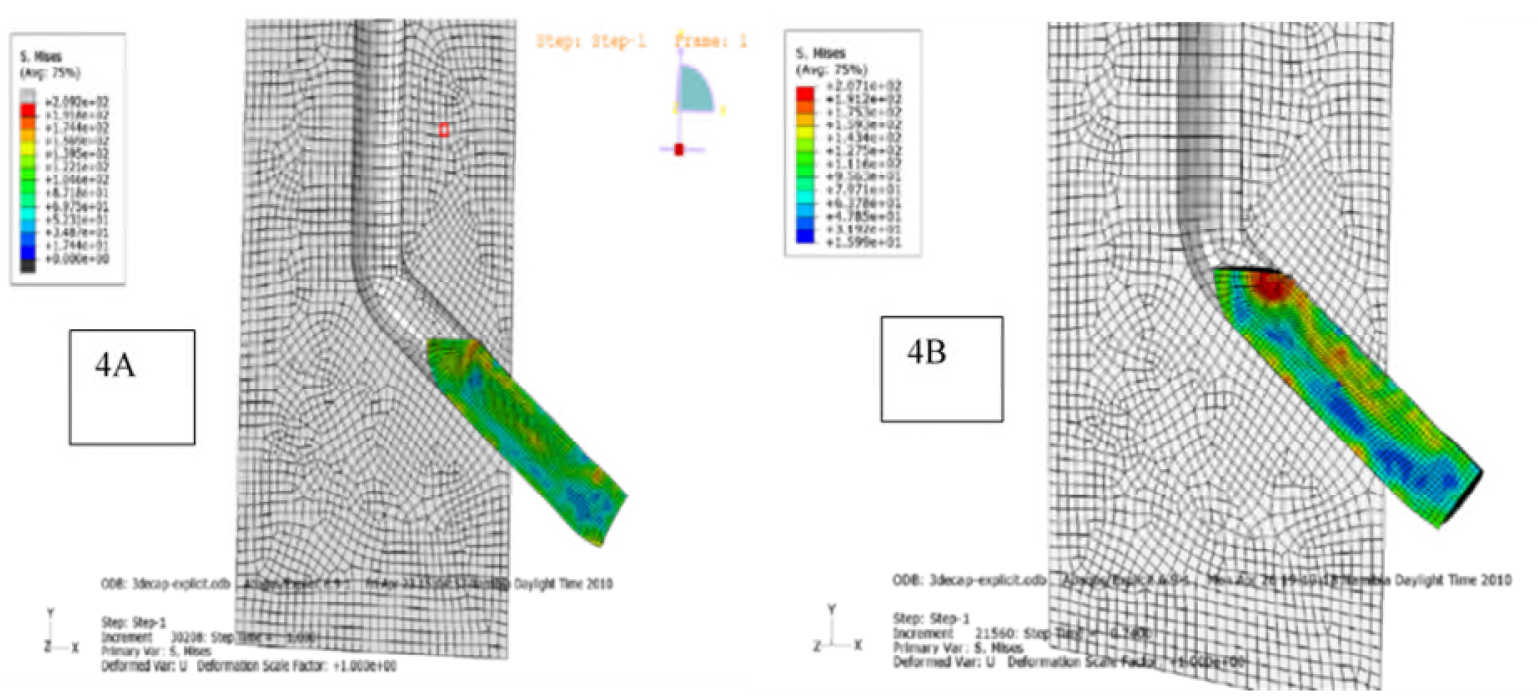

Fig. 4A shows the distribution of the effective stress obtained at time $\mathrm{t}=1.000(\mu=0.0)$ and $4 \mathrm{~B}$ shows the distribution of the effective stress obtained at time $\mathrm{t}=1.000(\mu=0.1)$

\section{Conclusion}

The finite element method technique has been developed to study the deformation behaviour and shape of the sample considering the geometry and boundary conditions in the ECAP process. A few different geometrical and constraining conditions have been simulated by varying frictional behaviour between the die and work-piece. The conclusions of the analysis are as follows:

1. The microstructure analysis of different parts of processed samples shows that the areas of lowest equivalent plastic strain exhibit an almost un-deformed microstructure. A lower equivalent plastic strain and a wider extension of outer less deformed zone.

2. The materials flow patterns observed are very similar to the experimental results.

3. The von Mises distributions varies during the deformation process and there is a steady and uniform region of maximum von Mises stress distribution and uniform region of maximum equivalent von Mises stress distribution in the work-piece, even though there is certain in homogenous deformation in the local zones of the work-piece.

4. From the simulations results, the extent of inhomogeneous in the work-piece shows increase due to the frictional effects and this have a great influence on the deformation behaviour during ECAP process and the effect is particularly severe at the bottom of the work-piece.

\section{Acknowledgement}

The authors gratefully acknowledge the financial supports of the National Research Foundation (NRF) South Africa, Faculty of Engineering and the Built Environment, University of Johannesburg, Johannesburg, South Africa

\section{References}

[1] M. Furukawa, Z. Horita, M. Nemoto, T. Langdon, The use of Severe Plastic Deformation for microstructural control, Mater. Sci. Eng. A, 324 (2002) 82-89.

[2] M. M. El-Rayesa, E. A. El-Danafa, The influence of multi-pass friction stir processing on the microstructural and mechanical properties of Aluminum Alloy 6082, Mater. Proc. Tech. 212 (2012) 1157-1168.

[3] P. Berbon, N. Tsenev, R. Valiev, M. Furukuwa, Z. Horita, M. Nemoto, Fabrication of bulk ultrafine-grained materials through intense plastic straining, Metall. Mater. Trans. 29 (1998) 2237-2243. 
[4] Z. Horita, M. Furukawa, M. Nemoto, T. G. Langdon, Development of fine grained structures using severe plastic deformation, Mater. Sci. Tech. 16(11-12) (2000) 1239-1245.

[5] T. Langdon, Processing by severe plastic deformation: Historical developments and current impact. Mater. Sci. Forum, 9(4) (2011) 667-669.

[6] H. Gleiter, Nanostructured materials: Basic concepts and microstructure, Acta Metall. 48 (2000) 1-29.

[7] M. Furukawa, Z. Horita, M. Nemoto, T. Langdon, The use of Severe Plastic Deformation for microstructural control, Mater. Sci. Eng. A. 324 (2002) 82-89.

[8] Y. J. Kwon, I. Shigematsu, N. Saito, Production of Ultra-Fine Grained Aluminum Alloy using Friction Stir Process, Mater. Trans. 44(7) (2003) 1343-1350.

[9] K. Kurzydlowski, Microstructural refinement and properties of metals processed by Severe Plastic Deformation, Bulleting of the polish academy of sciences and technical sciences, 52 (2004) N4. 